Article

\title{
Behind the Comments Section: The Ethics of Digital Native News Discussions
}

\author{
Orge Castellano Parra *, Koldobika Meso Ayerdi and Simón Peña Fernández \\ Department of Journalism II, University of the Basque Country, 48940 Leioa, Spain; \\ E-Mails: orgeluvin.castellano@ehu.eus (O.C.P.), koldo.meso@ehu.eus (K.M.A.), simon.pena@ehu.eus (S.P.F.) \\ * Corresponding author
}

Submitted: 15 December 2019 | Accepted: 3 February 2020 | Published: 16 April 2020

\begin{abstract}
Initially offered as a digital public sphere forum, comments sections became the preferred democratic arena for gatekeepers to encourage their readers to engage in constructive dialogue about relevant issues. However, news sites require commenters to remain civil in their interactions, which led users to seek alternative ways of commenting on the news. This article explores in-depth the contents of a sample of 98,426 user-comments collected between February-March 2019 from three major Spanish digital native newspapers: ElDiario.es, ElEspañol.com, and ElConfidencial.com. The main goals were to analyze whether comments in news outlets are deliberative, to assess the quality of the debate that takes place in them, and to describe their specific features. Discourse ethics were explored to determine the discussions' impact, the language used, the acceptance of arguments, and the recognition and civility of participants. Findings reveal that comments sections in news outlets do not have a dialogic nature and that the debates have a low-quality profile. Nonetheless, the degree of mutual respect in interaction is acceptable, with slightly observed levels of incivility. Finally, the data suggest that the focused comments are higher on social media and that memes and emojis represent a new form of digital discourse.
\end{abstract}

\section{Keywords}

discourse ethics; native digital media; new media; newspapers; social media; user-generated content

\section{Issue}

This article is part of the issue "Digital Native News Media: Trends and Challenges" edited by Ramón Salaverría (University of Navarra, Spain).

(C) 2020 by the authors; licensee Cogitatio (Lisbon, Portugal). This article is licensed under a Creative Commons Attribution 4.0 International License (CC BY).

\section{Introduction}

On a global scale, unimaginable before, places, communities, and networks have emerged online (Bowen, 1996; Goode, 2009), allowing their members to discuss topics that matter and to share openly and freely specific common interests and ideas inside flourishing digital ecosystems (Papacharissi, 2004). Online discourse has increased political participation strengthening citizen rights (Cammaerts \& Audenhove, 2005) while at the same time, new information and communications technology innovations, like the popularisation of the smartphone, have helped revive the public sphere (Ruiz et al., 2011). Despite the benefits of this digital transforma- tion, engagement has also brought up negative nuances as well. As the amount of information available online increases, and as more people started to take part in the online public sphere and on social platforms like Twitter and Facebook (Kies, 2010), the number of discourse problems has skyrocketed (Aurigi, 2016). Hate speech (Waldron, 2012); fake news (Mcnair, 2018); misinformation (Vergeer, 2018) and incivility (Coe, Kenski, \& Rains, 2014) are just some of the today's most common issues facing online discourse. These difficult times make us question if we are witnessing the reinvention of digital journalism (Salaverría, 2019) and a new intricate discourse reality within online public spheres such as news outlet comments sections. In light of the preced- 
ing, the importance of analyzing discursive ethics from the readers' comments in native digital media is crucial, since there is currently a research gap in this area. The current study examines explicitly online newspapers, a digital medium that has not yet been addressed in existing studies on participation and online discourse ethics. Three native digital news publications of reference in Spain are analyzed, including their comments sections and their official pages on Twitter and Facebook.

\section{Literature Review}

User-generated content in the form of comments constitutes a way of capturing the degree of the users' commitment with the news, since, when choosing to leave a contribution below a story, the user is showing an interest in its content, the newspaper's brand and the deliberative component of such interaction (Hermida, 2011; Ksiazek, Peer, \& Lessard, 2016; Meltzer, 2015; Ruiz et al., 2011; Springer, Engelmann, \& Pfaffinger, 2015; Weber, 2014; Ziegele, 2016). Experts in the field have highlighted the opportunities and challenges for journalists presented by the comments and the intricate dynamic between the media and users (Paskin, 2010; Rowe, 2014; Ruiz et al., 2011; Springer et al., 2015). Others have pointed out the democratic and plural aspect of the comments and their potential to shape public opinion (Dahlberg, 2011; Goode, 2009; Papacharissi, 2004; Stromer-Galley \& Wichowski, 2011; Weber, 2014).

Comments published in the media have not always lived up to the expectations of the theorists who defend the deliberative character of public opinion construction (Stroud, Jomini, Scacco, \& Curry, 2015). Providing the opportunity to comment on the news has been one of the most consistent and widely implemented strategies of the mainstream media (Graham \& Wright, 2015; Stroud, Scacco, \& Curry, 2014; Ziegele, 2016) mainly because comments contribute to attracting users, promoting brand loyalty and encouraging engagement (Goodman \& Cherubini, 2013). Comments allow users to participate in a discussion on the topics covered in the news stories, in addition to voicing their opinions and sharing ideas (Ruiz et al., 2011). From a liberal perspective, the comments are a sign of the political times and the deep globalization of sources of information. They belong to a new period of deliberative digital democracy (Dahlberg, 2011). In this regard, comments sections provide a democratic space for users outside traditional channels. Comments sections are being used to dispute news stories, to argue, to communicate with other readers, and to learn. (Robinson, 2010, p. 137). Tenenboim and Cohen (2015) imply that user comments have a role to play in building social and community identity, such as political issues and controversies do on news articles. According to Robinson (2010, p. 137), people posting comments value the ability to exercise freedom of speech. They expect openness, mutual respect, and a self-moderated framework that assesses the comments within the community.
Comments are an asset in any story because they enable public discussion of issues and thereby serve as a tool for deliberation (Springer et al., 2015). However, while both journalists and audiences (Barnes, 2015; Meltzer, 2015) find the presence of comments in the media enriching, both groups express concern about the quality of the discussions taking place (Anderson, 2011; Springer et al., 2015). Clearly, without human interaction, there will not be comments; social media could not have a place online (Sobieraj \& Berry, 2011). Nevertheless, this same humanity is what makes the Internet a problematic, complicated place. In this milieu, several authors have provided operational definitions of what incivility looks like. These definitions include vulgarity, stereotypes, and insults (Chen, 2017; Gervais, 2015). Other definitions include the use of irony to mock people or situations, name-calling, hyperbole, or rudeness (Gervais, 2013). As Chen (2017, p. 5) states, "Incivility can be a slippery notion. What constitutes incivility varies from person to person, so it is difficult to come up with a rule of what incivility means or even describe discourse that is consistently viewed as uncivil."

In many cases, user-comments do not meet the basic standards of mutual respect, as they are often uncivil and irrational (Diakopoulos \& Naaman, 2011; Rowe, 2015). Though only a handful of contributions enrich and encourage a lively debate (Masip, 2011), more and more frequently, these comments are mixed with insults, derogatory remarks, or racist and xenophobic slurs. As Larsson (2018, p. 618) points out, "Internet is perceived-from a free-for-all utopia of public discussion, to more problem-laden rhetoric surrounding the hate speech and bitter rhetoric that one is likely to happen upon in forums such as newspaper comment fields." Nonetheless, the presence of a higher degree of controversy and uncivil behavior among readers cannot be considered generalized in the comment sections, since the moderation and user registration policies developed by the media contribute to ensuring that the general tone of the debates does not exceed the discourse limits (Domingo, 2015; Ksiazek, Peer, \& Zivic, 2015). When it does, it is usually focused on quite specific themes and targets (Coe et al., 2014), such as immigration, women, and minorities (Chen et al., 2018; Gardiner et al., 2016). For Hwang, Kim, and Kim (2018), incivility is operationalized as simple "disrespectful statements or attacks" toward someone else. Hence, an uncivil discourse has also been defined as that in which "communication violates the norms of courtesy of a given culture" (Mutz, 2015).

Conversely, as Wessler (2008) states, for it to be indeed a space that feeds deliberation, user discourse has to be reasoned, that is, the participants must provide evidence and reasons for the statements. The discourse must also be civil; that is, the comments must be transmitted politely and respectfully. Civility and reasoning are two critical features of deliberative discourse (Freelon, 2015). Civility is a crucial concept in political deliberation (Gastil, Deess, \& Weiser, 2002; Min, 2007). It 
refers to the attitude shown by people who view each other with mutual respect (Andersson \& Pearson, 1999; Brooks \& Geer, 2007) and who conform to basic rules of courtesy. Jamieson, Volinsky, Weitz, and Kenski (2017) point out that civility underlies all discourse that does not silence or eliminate different points of view, but instead manifests respect. Thus, civility is a central component of the debate that requires respect and enables the presence of different points of view (Stryker, Conway, \& Danielson, 2016). However, while civility is more focused on norms that promote the collective good, politeness, or cordiality, incivility conveys messages that use an unnecessarily disrespectful tone (Coe et al., 2014). For example, ad hominem fallacies fall into this definition. Ad hominem fallacies are when a user refers negatively toward the social construct of another (Gervais, 2015). Incivility has also been examined within story categories. Politics (national affairs), economy, and sports often generate high levels of incivility (Coe et al., 2014; Muddiman \& Stroud, 2017). The incivility present in politics and public affairs is particularly relevant in that it causes cracks in spaces of deliberation and citizen participation that are at the heart of digital democracy (Herbst, 2010; Stromer-Galley \& Wichowski, 2011). Recently, Weber et al. (2020) found that reading uncivil and hateful user comments against refugees negatively impacted participants' attitudes towards them, even exerting indirect effects on prosocial behavior.

Moreover, new research has shown that between $22 \%$ and $33 \%$ of the comments posted on the sites and Facebook pages of multiple regional and national media include derogatory words, profanity, or unfounded accusations of misinformation (Coe et al., 2014; Su et al., 2018). Nevertheless, for the scholar Papacharissi (2004), incivility has a purpose, and that is to disrupt the collective roots of democracy. According to her study, the messages that should concern us the most are those that, while being courteous, threaten democratic traits or use antagonistic stereotypes. Another core component of incivility is the anonymity that is permitted in online spaces and how it affects the level of discussion, allowing for higher levels of incivility (Graf, Erba, \& Harn, 2017; Lapidot-Lefler \& Barak, 2012). Alternatively, while anonymity has permitted an increase in flaming and incivility, it also has the advantage of reflecting more honest, emotional opinions, which may, therefore, be further representative of the users' discourse (Papacharissi, 2004). Anonymity is, consequently, one of the central concerns in the nature of online discussions as it can be considered both beneficial and harmful (Witchge, 2014). When eliminated, the level of civility in the comments within the newsmedia sites increases significantly, notwithstanding their suppression reduces the number and variety of opinions (Santana, 2014).

In the media, very often quantity takes precedence over the quality of comments (Masip, 2011). A quality that, following Habermas $(1984,1992)$, should be measured by the presence of argumentation, logic, and co- herence of arguments, the search for collective truth, the recognition of the counterpart and respect in dialogue. Similarly, the media have acknowledged their responsibility in fostering high-quality user debates on their digital platforms (Ksiazek, 2018). Most importantly, there is a notable difference between cross-platform user-generated content. Rowe (2015) found that discourse quality varied, adding "website commenters are more likely to engage in higher-quality discussion than Facebook commenters" (Rowe, 2015, p. 552). This characteristic may be influenced-not only by the fact that the media moderate user-generated content-but also by the fact that user engagement with news articles on social media is characterized by short, emotional, and consensual comments (Ben-David \& Soffer, 2019). Indeed, the media tend to divert the participation of their readers towards social networks (Larsson, 2018), which reduces the presence of anonymous comments and improves their quality (Hille \& Bakker, 2014). An increasing number of media outlets are removing comment sections from their websites and instead focusing their efforts on building online communities on their Facebook pages (Ellis, 2015). It is important to note that Facebook adheres to a real name policy, which implies, among other things, that users act in a more honest, civic manner (Su et al., 2018; Toma, Hancock, \& Ellison, 2008). However, some highlight Twitter as a suitable medium for fostering social dialogue (Williams, RussellMayhew, Nutter, Arthur, \& Kassan, 2018). Twitter is a rich source of data containing diverse views and perspectives from a wide range of individuals (Apoorva, Vaishnav, Chowdary, \& Uddagiri, 2016). The simple presence of an open comment section on online media pages negatively influences the perception of the media's credibility (Conlin \& Roberts, 2016; Prochazka, Weber, \& Schweiger, 2018). However, even though both Facebook and Twitter are the two most popular platforms for public debates, users mostly prefer to make comments on the pages of the media themselves, as they can probably express themselves more frankly than in the case of a social network, in which, moreover, comments are automatically shared with friends, family, and acquaintances (Hille \& Bakker, 2014). As a result, in the case of the media, the activity and debate of users are perhaps more extensive and of higher quality in the comments section of the media itself than on its Facebook page (Rowe, 2015). As Ben-David and Soffer (2019) point out, readers' comments on the same news on different platforms can vary significantly based on each platform's cultural practices and technological affordances, which, in turn, shape the public discussion of news. Although social networks can offer newspapers an important source of interaction, interactivity reduces over reactivity, i.e., the private response from one user to another without a dialogical character (Carey, 2014). Interestingly, it is this reactivity that seems to favor a lack of courtesy in the comments, which is more moderate in cases where there is debate among readers through the comments (Coe et al., 
2014). Alternatively, and as summarized by Strandberg and Berg (2013), "Online reader comments function as a mix of both platforms for democratic conversations and virtual soapboxes."

\section{Methods}

\subsection{Research Corpus}

For the development of this study, we have chosen multiple methodological frameworks composed of several techniques. Qualitative and quantitative methods complement each other. By examining the research question from two different perspectives, one can get a better perspective on the social phenomenon under study, namely the deliberative dynamics of user-comments within digital newspapers. A qualitative textual analysisusing the normative approach of Habermas' (1984) discourse ethics-was applied in the sample of comments collected. According to Habermas' theory, for the discourse to be valid, truth, clarity, sincerity, and legitimacy have to take place inside the conversation so that any of the conversation's participants can call them into question. His theory also aims to outline the conditions for rational argumentation based on the moral behavior of the members in the discussion (Habermas, 1992). For our study, Habermas' approach is appropriate because it allowed us to fully examine and interpret the body of user-generated content within the comments section located below each news article, as well as outside the comments sections in official accounts on Facebook and Twitter. The selected corpus was composed of three general-interest native digital newspapers available nationwide: EIDiario.es, ElEspañol.com, and ElConfidencial.com. The digital nature of these newspapers played an important role in their selection. The news outlets studied are among the most visited in Spain (Newman, Fletcher, Kalogeropoulos, \& Nielsen, 2019). Their informative dissemination has considerable relevance in Spain and possesses a substantial presence in social networks. In our sample, we examined, by hand, the discursive ethics of a one-month cluster sample of comments. Comments were collected from stories belonging to the "most read" section of the day. These news items were taken from the landing page of each one of the news outlets chosen for analysis. News items were gathered in two-time sessions, in the morning at 10:00 and the evening at 22:00. For each domain, we aimed to gather a somewhat equal number of news pieces. On average, this resulted in six stories per session. At the evening session, news stories that remained high in the ranking were updated for new recordings. This method allowed us to work with a consistent and more balanced dataset. Accordingly, in quantitative terms, we initially set up an average number of comments generated during the sampling period. We collected data on the most commented news sections and frequency of users per news outlet, the number of users by username type, and impacts-shares, likes, retweets-on social media, and the amount of user-generated content such as emojis and memes. Data were controlled and measured by combining cross-sectional analysis with content analysis (Krippendorff, 2018), which provided us with a deeper understanding of the data collected at the same point in time in a representative subset. We have defined the following research questions:

RQ1: Do the news outlets comment sections have a deliberative nature?

RQ2: What is the quality of the debate that users make in the comments section? Does incivility influence the dynamics of the discursive ethics of user comments?

RQ3: What kind of specific features do the comments have based on their distribution platform?

\subsection{Case Study}

We have chosen a case study approach because we consider it appropriate when researching contemporary phenomena in a real context. In our case, the study of the discourse ethics within user-comments from digital-only newspapers in Spain and social networks. We performed qualitative textual analysis performed in a fully manually fashion-using the normative approach of Habermas' discourse ethics (Habermas, 1984)- of the conversations generated by users. This analysis was completed using a codebook (Habermas, 1984, 1992; Masip, Noci, Domingo, Micó, \& Ruiz, 2012; Ruiz, Massip, Micó-Sanz, Díaz-Noci, \& Domingo, 2010) that collected and classified the contributions generated by the users at the bottom of the news pieces, with a specific focus on the comments. Following these criteria, we used content analysis, which allowed, in addition to obtaining a qualitative view of the comments, to acquire nuances of a quantitative nature as well (Kothari, 2004). Accordingly, in quantitative terms, we initially established an average number of comments generated during the sampling period, the frequency of comments and most commented news sections by news outlet, and the number of users based on their preferred username. Data was measured using the quantitative computer-assisted qualitative data analysis software, Nvivo 12 . The use of different methodological techniques allowed us to complete a cross-sectional analysis, which gave us a deeper understanding of data collected at the same point in time in a sample population and a representative subset.

\section{Sample and Data Analysis}

The sample covered a compound month, that is, taking the first day of the week, in this case, the first Monday of the first month of the sample, and from there, alternating one day on, one day off until we obtained 30 days of 
date from a total of eight weeks. We started on February 1st, 2019, and completed data collection on March 27th, 2019. The reason for this sampling method was to ensure that the same stories did not repeat in the next sampling session. For the selection of the sample, a cluster sampling method was chosen. In the first phase, we captured the comments below each article belonging to the "most-viewed" section from the day of the sample. Data was gathered from the landing page of each of the digital news outlets studied. For social networks, due to the vast amount of data captured, only the story with the most comments on a particular day was chosen for final coding. It is worth noting that due to the restrictions of the Facebook comment ranking algorithm, only those comments available in each post could be used for analysis. Since July 2019, comments available on public pages

Table 1. User-comments discourse ethics codebook.

\section{Identification Record}

\begin{tabular}{cccc}
\hline No. datasheet: & Putlet: & Sample date: & Total comments: \\
\hline & Il. Information Concerning the Conversation & News Section: \\
\hline No. of users: & $\begin{array}{c}\text { No. of mentions } \\
\text { among users }\end{array}$ & No. of replies: & Average \\
Presence of links & $\begin{array}{c}\text { Presence of ads or } \\
\text { self-promotion }\end{array}$ & Contrast with other media & Contrast with other sites
\end{tabular}

\section{Social Networks}

\begin{tabular}{llllll}
\hline & Facebook & & & Twitter \\
\hline No. of comments & No. of shares & No. of likes & No. of comments & No. of retweets & No. of likes \\
No. of memes & No. of GIFs & No. of emojis & No. of memes & No. of GIFs & No. of emojis \\
\hline
\end{tabular}

\section{Discourse comment ethics}

\section{Logic and coherence}

\section{Coding Segment}

a. Do users focus on the topic of the news story?

b. Do users try to argue the point?

\section{Discourse rules}

1.1. No speaker may contradict themselves

1.2. Every speaker who applies predicate $F$ to object $A$ must be prepared to apply $F$ to all other objects resembling $A$ in all relevant respects

1.3. Different speakers may not use the same expression with different meanings

\section{Collective search for truth}

a. Do users respect and acknowledge each other as valid members of the conversation?

b. Does the comment contain incivility, profanity, or derogatory remarks?

c. Do users provide a different point of view than other comments?

d. Do users question each other and ask for clarification on expressed views?
2.1. Each speaker may only asset what he/she himself/herself believes

2.2. Messages containing name-calling, aspersion, vulgarity derogatory or/and abusive language, racist remarks, insults will be coded as uncivil

\section{An agreement based on the best argument}

a. Do users endorse an argument of another user?

b. Do users mention or refer to other sources?

c. Are the sources related to the point of view of most of the users?
3.1. Every subject with the competence to speak and act is allowed to take part in a discourse

3.2. Everyone is allowed to question any assertion, whatever.

3.3. Everyone is permitted to introduce any assertion whatever into the discourse 
are not shown or ranked as they previously did before, where users saw all comments all the time regarding engagement or post popularity (Shen, 2019). This new rollout affects the reach of comments on public posts from Facebook's 'Pages' and people's 'News Feed' equally. The new feature, called 'comment ranking' patented in the US under the name 'Systems and Methods for Ranking Comments,' ranks comments under a quality signals basis, which means users only see public comments that are timely and relevant to them (Owens, 2017).

For our data collection, we used Ncapture, a plugin browser of Nvivo. The sample had a pre-established schedule beginning at 10:00 in the morning and ending at 23:59 the same day. We applied a model adapted analysis datasheet, which was based on the theoretical framework of the discursive ethics of the philosopher Jürgen Habermas $(1984,1992)$ who believed that dialogue is a set of ethical, rational and moral standards that enable the construction of society and public opinion and therefore has the potential to become the engine for social change. We also applied the methodology of Masip et al. (2012). Each comment was coded into a datasheet, structured upon three discourse segments: 'Logic and Coherence,' 'Collective Search for Truth,' and 'An Agreement Based on the Best Argument.' Each one represents a coding reference followed by a set of questions aimed to answer RQ1 and RQ2 primarily. Therefore, a single comment can be classified into multiple sections depending on the versatility of the comment. Some comments could not be classified and were excluded from the sample (e.g., deleted comments; comments with lack of sufficient argumentation such as spam or advertisements, flagged comments). As aforementioned, every coding category was supported by a series of questions to frame each discursive ethical aspect and perform a qualitative assessment (Table 1). Consequently, each of these questions was preceded by a measurement system, based on one affirmative (yes) and one negative (no) criteria. On social networks, besides from the qualitative assessment carried on comments, a quantitative analysis was applied in order to complement evidence to answer RQ3.

\section{Results}

During the study period between February 1st, and March 27th, 2019, a dataset of 704 stories, and a total of 98,426 comments for all news outlets was obtained (Table 2). ElDiario.es was the news site that produced the most comments, representing $38 \%$ of the total sample, followed by ElEspañol.com (31.1\%) and ElConfidencial.com (30.5\%). On social networks, 56,611 comments were collected; however, due to data restrictions, both on Facebook and Twitter, only 13,811 comments on Facebook (25\% of the total) and 8,880 on Twitter (51\% of total) were coded.

From all the comments gathered, 17,466 users, resorted to using a nickname and 9,823 picked their proper name to comment. The registration mechanisms in each news outlet do not prohibit one user from registering multiple nicknames. Therefore it is not possible to ensure that all participants were different individuals. Nicknames on social networks were scarcely recorded; for example, only 423 people commented with a nickname on Facebook. In Spain, most users prefer to identify themselves using their proper names. That said, a minority of users did use their initials or partially combined names.

Most participants commented only once $(72.6 \%$; see Table 3). This figure is relatively consistent in EIDiario.es

Table 2. Number of comments collected per digital news outlet and social network.

\begin{tabular}{lccccrr}
\hline & Comments & Stories & Avg. Comments & Avg. Stories & Facebook & Twitter \\
\hline ElDiario.es & 11,839 & 294 & 422 & 10.5 & 39,539 & 4,927 \\
ElConfidencial.com & 9,632 & 205 & 344 & 7.3 & 8,714 & 699 \\
ElEspanol.com & 9,464 & 205 & 338 & 7.3 & 10,358 & 3,254 \\
Total & 30,935 & 704 & 1104 & 25 & 58,611 & 8,880 \\
\hline
\end{tabular}

Notes: Not all comments shown on Facebook, and as a result collected, were available for coding since the social network applies a comment ranking algorithm based on a quality signals basis (Owens, 2017; Shen, 2019). This means that users only see comments that are timely and relevant to them. Other variables included the ranking are posting time, content's overall quality, popularity, and users' previous reactions.

Table 3. Frequency of comments per users (\%).

\begin{tabular}{cccc}
\hline № of Comments & ElDiario.es & ElConfidencial.com & ElEspañol.com \\
\hline 1 & 67 & 57 & 94 \\
2 & 17 & 20 & 5.0 \\
3 & 7.0 & 10 & 1.0 \\
4 & 2.7 & 3.9 & 0.0 \\
5 to 9 & 4.3 & 5.9 & 0.0 \\
10 to 14 & 1.0 & 2.0 & 0.0 \\
$15-25$ & 1.0 & 1.0 & 0.0 \\
$\geq 25$ & 0 & 0.7 & 0.0 \\
\hline
\end{tabular}


and ElConfidencial.com. However, it rose drastically to 94\% in ElEspañol.com. By engaging in only one contribution, users do not invest themselves in the debate. Fourteen percent of users engaged twice. Both Eldiario.es and ElConfidencial.com have users who post more than half a dozen times. This figure includes a group of between $2 \%$ and $3 \%$ of community members who appear to engage in almost every news article we reviewed.

The analysis of the discourse language elements on social networks considered the presence of memes, emojis, and animated GIFs in the comments. In the case of memes, we found that the users of ElEspañol.com use them the most with $3.4 \%$ of comments on Facebook containing memes, whereas ElDiario.es comes in first on Twitter (1.8\%). The memes tend to have a political and sarcastic tone. In the case of emojis, the majority recorded tend to be unaccompanied by any text. The presence of GIFs to convey an idea or argument is still scarce, yet figures are entirely consistent across sites (Table 4). It can be argued that Facebook's new algorithm for comment ranking has limited the number of low-quality comments on public pages. In our sample, we could verify that comments with a poor grammatical or syntactic structure-containing short phrases, an emoji, a GIF, a link, or an Internet shorthand acronym such as 'LOL' or 'Hahaha'-were ranked lower than comments with a more substantial amount of characters.

\subsection{Logic and Coherence}

Another element to discern the degree of logic and coherence in a conversation is whether the speakers intend to argue about the topic being discussed. Although some digital news outlets have a high number of comments, the majority of users do not stay on topic in the conversations even after automatic post-moderation and before user flagging. An essential number of comments recorded are not linked to the issue present in the published story. In contrast, lively discussions take place in the comment threads. However, consistently across news outlets, a vast majority of participants end up debating topics or issues that have no direct relationship with the current event. Barely 1/10 of ElDiario.es' comments are about the news issue introduced by the editor in the article. This figure roses on ElConfidencial.com and is higher on ElEspañol.com (Table 5). On social media, the overall amount of focused user-contributions is significantly higher on Facebook (21.3\%) than on Twitter (4.8\%).

A low number of argumentative comments are written. Most users do not introduce new arguments against points of view expressed by other members of the discussion. Deliberative engagement is barely present; the dialog is intense and tends to be civilized, yet users lack the habit of arguing or accepting, even similar points made by another like-minded participant or adversary. Figures obtained are identical in almost all newspapers, with ElDiario.es coming on top with $9.4 \%$ of argumentative comments coded (Table 6). The relevance of the current affairs of most conversations meant that users tend to get carried away by them and have virtually almost no intention of continuing arguing their points or those from another user. On social media, argumentative comments arise on Twitter and include $10.2 \%$ of comments, whereas, on Facebook, they account for $6.9 \%$ of comments.

\subsection{Collective Search for Truth}

Regarding the degree of mutual respect in the interaction, generally speaking, users respect and acknowledge each other as valid members of the conversation.

Table 4. Presence of digital discourse language elements on social networks (\%).

\begin{tabular}{lcccccc}
\hline No of Comments & \multicolumn{3}{c}{ Facebook } & \multicolumn{3}{c}{ Twitter } \\
\cline { 2 - 7 } & Emoji & GIF & Meme & Emoji & GIF & Meme \\
\hline EIDiario.es & 7.2 & 0.8 & 0.4 & 4.3 & 1.5 & 1.8 \\
ElConfidencial.com & 6.8 & 1.2 & 0.03 & 1.9 & 0.6 & 0.24 \\
EIEspanol.com & 9.1 & 2.2 & 3.4 & 4.8 & 1.4 & 1.5 \\
\hline
\end{tabular}

Table 5. Do users focus on the topic of the news story?

\begin{tabular}{|c|c|c|c|c|c|c|}
\hline & \multirow[b]{2}{*}{ Focused Comments } & \multirow[b]{2}{*}{$\%$} & \multicolumn{2}{|l|}{ Facebook } & \multicolumn{2}{|l|}{ Twitter } \\
\hline & & & Focused comments & $\%$ & Focused comments & $\%$ \\
\hline EIDiario.es & $\begin{array}{c}1,113 \\
(N=11,839)\end{array}$ & 9.4 & $\begin{array}{c}1,485 \\
(N=7,317)\end{array}$ & 20.2 & $\begin{array}{c}105 \\
(N=2,165)\end{array}$ & 4.8 \\
\hline ElConfidencial.com & $\begin{array}{c}1,448 \\
(N=9,464)\end{array}$ & 15.3 & $\begin{array}{c}692 \\
(N=3,239)\end{array}$ & 21.3 & $\begin{array}{c}96 \\
(N=390)\end{array}$ & 2.9 \\
\hline ElEspanol.com & $\begin{array}{c}1,560 \\
(N=9,632)\end{array}$ & 16.2 & $\begin{array}{c}748 \\
(N=3,325)\end{array}$ & 22.4 & $\begin{array}{c}231 \\
(N=2,052)\end{array}$ & 6.9 \\
\hline
\end{tabular}


Table 6. Do users try to argue their point?

\begin{tabular}{|c|c|c|c|c|c|c|c|c|c|}
\hline & \multirow[b]{2}{*}{ Comments coded } & \multirow[b]{2}{*}{ Argumentative comments } & \multirow[b]{2}{*}{$\%$} & \multicolumn{3}{|c|}{ Facebook } & \multicolumn{3}{|c|}{ Twitter } \\
\hline & & & & $\mathrm{CC}$ & $A C$ & $\%$ & $\mathrm{CC}$ & $A C$ & $\%$ \\
\hline EIDiario.es & 11,839 & 1,079 & 9.1 & 7,317 & 526 & 7.1 & 2,165 & 296 & 13.6 \\
\hline ElConfidencial.com & 9,464 & 698 & 7.3 & 3,239 & 237 & 7.3 & 390 & 237 & 7.2 \\
\hline ElEspanol.com & 9,632 & 646 & 6.7 & 3,325 & 211 & 6.3 & 2,052 & 327 & 9.8 \\
\hline
\end{tabular}

The presence of incivility, profanity, or derogatory remarks is low (Table 7). When present, these sorts of remarks are mostly used against personalities in the stories (politicians and celebrities) and power structures, and not against other contributing members. In total, $12.7 \%$ of all contributions contain incivilities.

It is also shown that there are derogatory remarks, and when present, these tend to be leveraged at specific social groups. This includes citizens belonging to minority groups: women, LGBTQ members, and immigrants (Chen et al., 2018; Ziegele, Breiner, \& Quiring, 2014). On Facebook, fewer derogatory comments are perceived, although they are slightly more prominent in the comment sections of the analyzed media and higher on Twitter (Table 7).

The second question to be dealt with in this section is whether users who focus their interventions on the topic under discussion provide numerous or different points of view. We can state that in the analyzed conversations, pluralism is strongly resented. The conversations frequently have a polarized tinge: the majority and minority viewpoints, each of the members belonging to these two groups, are enclosed within their own arguments, which leads to a gradual deterioration of the quality of the comments, discursive clutter and abusive language are observed as well. All these factors are the cause of polarization. Few voices try to add a third approach and introduce other points of view. Substantive dialogue can only become valid; only the intentions of the actors are clear. However, the prerequisite of engagement in substantive debate, is that one's intentions must be fully accessible to the examination and challenge of others. The willingness to verify authenticity is itself a crucial part of the discussion. Without these motives, there cannot be any cooperative search for truth (Habermas, 1992). In the newspapers included in the corpus of the sample, these statements are tangible. In practically no case do the results exceed the $10 \%$ threshold, except in ElEspañol.com, which obtains $9.4 \%$ of different points of view in its debates on its Facebook page (Table 8).

\subsection{An Agreement Based on the Best Argument}

Users usually do not support other users' argument. The overall percentage on the news outlets was 3.3\% and on social networks $2.9 \%$. The sources provided or mentioned by the participants were virtually nonexistent across all media analyzed, with an overall of $6.7 \%$. Sources were barely used and, in cases where they were used, were usually not related to the topic being discussed. Readers do not cite sources that complement, nuance, or broaden their viewpoints or the opinion of other users. The few sources observed generally are not focused on improving the debate but on generating conflict or controversy, and most of them are related to the ideological struggles of the users themselves, moving away from the subject of the discussion.

Table 7. Presence of incivility, profanity and derogatory remarks (\%).

\begin{tabular}{lccc}
\hline & Total & Facebook & Twitter \\
\hline ElDiario.es & 4.9 & 3.2 & 8.8 \\
ElConfidencial.com & 3.7 & 4.0 & 0.9 \\
ElEspanol.com & 4.1 & 2.5 & 8.5 \\
\hline
\end{tabular}

Table 8. Do participants provide different points of view and question each other and ask for clarifications on expressed views? (\%).

\begin{tabular}{|c|c|c|c|c|c|c|}
\hline & \multirow[b]{2}{*}{ Diverse Points of View } & \multirow[b]{2}{*}{ Users Asking for Clarifications } & \multicolumn{2}{|c|}{ Facebook } & \multicolumn{2}{|c|}{ Twitter } \\
\hline & & & DPV & UAC & DPV & UAC \\
\hline EIDiario.es & 5.4 & 5.5 & 2.9 & 4.2 & 5.4 & 14 \\
\hline ElConfidencial.com & 3.0 & 3.5 & 3.7 & 14.0 & 2.0 & 12 \\
\hline ElEspanol.com & 3.9 & 1.0 & 3.5 & 10 & 9.4 & 13 \\
\hline
\end{tabular}

Notes: DPV (Diverse points of view), UAC (Users asking clarifications). 


\section{Limitations and Directions for Future Research}

Despite the significance of our findings, our study also has certain limitations. First, the study is based on data that was collected during a limited period and, even though the digital news outlets selected for the sample are ranked as one of the most visited and relevant ones in Spain, further research should be carried out in order to analyze data over a more extended period. These analyses should include data from other minority news outlets to increase the scope and obtain more detailed aspects of the discourse ethics behind the comments sections. Therefore, our findings cannot be automatically generalized to the entire state of online discourse within the Spanish digital media. It is important to continue exploring alternative and potentially new discursive perspectives inside and outside the outlet's informative boundaries. Second, the limited number of Al technologies available, such as neural networks for discourse analysis, poses a significant challenge for any scientist trying to analyze large chunks of data. In-depth machine learning could be used to process more dimensions of the data, study outcomes from the past, and master the capacity to collect, understand and subsequently trace previous language patterns to help make judgments in real-time.

\section{Conclusions and Discussion}

The analysis of the comments of the readers in all three news outlets allows us, in the first place, to conclude that the comments do not have a deliberative nature. Three out of four users $(72.6 \%)$ only made one comment during the examined period. The presence of many unique comments precludes the existence of a fluid conversation between the readers. The significant number of individual users in the comments section fragments the debate. Moreover, while all members of the discussion have equal opportunities to post a comment, in almost of the comments sections of all the news outlets analyzed, a limited number of participants are responsible for the majority of the arguments and point of views expressed, which contributes to the monopolization of discourse by individuals and groups in online conversations (Jensen, 2016).

Second, the study reveals the low-quality profile of the debates that take place in the comments section of the news outlets. Still, most comments remain irrelevant to the issue being discussed, and a vast majority of users do not focus on the topic of the news story. Only $13.3 \%$ intend to argue the topic being discussed. Only a small number of users try to argue the point (7.8\%). Likewise, users rarely endorse an argument of another user or mention or refer to other sources. The difference between the data collected for social media platforms may be due to the effectiveness of moderation algorithms which are in charge of ranking low-quality content not related to the discussed topic.

The degree of mutual respect in interaction, a vital element of the democratic value of the discussion where speakers consider each other as legitimate members of the dialogue (Papacharissi, 2004), was calculated based on the existence of incivility, profanity, and derogatory remarks toward other users. In this regard, the study shows that overall of $12.7 \%$ of all contributions contains incivilities. It is worth pointing out that previous scholarship has recorded high levels of incivility in online participatory spaces (Coe et al., 2014; Gervais, 2015); however, technological progress has allowed the emergence of more robust moderation systems and automatic moderation that have achieved the goal of keeping insults away from the comments section (Diakopoulos \& Naaman, 2011; Ruiz et al., 2010). Nonetheless, a significant number of negative comments still arise. Recognizing that there is a meager rate of deleted or moderated comments in online media, it seems clear that users try to avoid offending others directly and try to express their anger or hate with other rhetorical tactics, such as irony, sarcasm, and jokes. While insults are easily detected by filtering software and algorithms, and most of the time, they are recognized by automated moderators; demeaning dialect involves further rhetoric subjective assessment.

Finally, and related to the above, the study also shows that the comments section of digital news media and social networks have other specific patterns and features based on their distribution platforms. These include emojis, memes, or animated GIFs. They all are a form of graphic communication used for social commentary on a wide variety of topics (Meso-Ayerdi, Mendiguren-Galdospin, \& Pérez-Dasilva, 2017) and their use allows users to synthesize an idea, scenario, or statement in a simple and agile way (Freire, 2016; Gómez-García, 2013).

\section{Acknowledgments}

This research was supported by the Spanish Ministry of Science, Innovation and Universities ("News, Networks and Users in the Hybrid Media System: Shared Creation and Dissemination of News in Online Media," RTI2018095775-B-C41). It was carried out within the Consolidated Research Group 'Gureiker' (A) (IT1112-16), funded by the Basque Government.

\section{Conflict of Interests}

The authors declare no conflict of interest.

\section{References}

Anderson, C. W. (2011). Between creative and quantified audiences: Web metrics and changing patterns of newswork in local US newsrooms. Journalism, 12(5), 550-566.

Andersson, L. M., \& Pearson, C. M. (1999). Tit for tat? The spiraling effect of incivility in the workplace. Academy of Management Review, 24, 452-471. https://www.doi.org/10.2307/259136 
Apoorva, G., Vaishnav, N. R., Chowdary, E. D., \& Uddagiri, C. (2016). An approach to sentiment analysis in Twitter using expert tweets and retweeting hierarchy. In 2016 International conference on microelectronics, computing, and communications (MicroCom) (pp. 1-8). Durgapur: IEEE.

Aurigi, A. (2016). Making the digital city: The early shaping of urban Internet space. Aldershot: Ashgate.

Barnes, R. (2015). Understanding the affective investment produced through commenting on Australian alternative journalism website New Matilda. New Media \& Society, 17(5), 810-826.

Ben-David, A., \& Soffer, O. (2019). User comments across platforms and journalistic genres. Information, Communication \& Society, 22(12), 1810-1829.

Bowen, C. (1996). Modem nation: The handbook of grassroots American activism online. New York, NY: Random House.

Brooks, D. J., \& Geer, J. G. (2007). Beyond negativity: The effects of incivility on the electorate. American Journal of Political Science, 51, 1-16.

Cammaerts, B., \& Audenhove, L. V. (2005). Online political debate, unbounded citizenship, and the problematic nature of a transnational public sphere. Political Communication, 22(2), 179-196.

Canter, L. (2013). The misconception of online comment threads. Journalism Practice, 7(5), 604-619. https:// www.doi.org/10.1080/17512786.2012.740172

Carey, M. C. (2014). Facebook interactivity rare on community news sites. Newspaper Research Journal, 35(2), 119-133.

Chen, G. M. (2017). Online incivility and public debate: Nasty talk. Berlin: Springer.

Chen, G. M., Pain, P., Chen, V. Y., Mekelburg, M., Springer, N., \& Troger, F. (2018). 'You really have to have a thick skin': A cross-cultural perspective on how online harassment influences female journalists. Journalism. https://doi.org/10.1177/14648849 18768500

Coe, K., Kenski, K., \& Rains, S. A. (2014). Online and uncivil? Patterns and determinants of incivility in newspaper website comments. Journal of Communication, 64(4), 658-679.

Conlin, L., \& Roberts, C. (2016). Presence of online reader comments lowers news site credibility. Newspaper Research Journal, 37(4), 365-376.

Dahlberg, L. (2011). Re-constructing digital democracy: An outline of four 'positions.' New Media \& Society, 13(6), 855-872.

Diakopoulos, N., \& Naaman, M. (2011). Towards quality discourse in online news comments. In P. J. Hinds, J. C. Tang, J. Wang, J. E. Bardram, \& N. Ducheneaut (Eds.), Proceedings of the ACM 2011 conference on computer supported cooperative work (pp. 133-142). New York, NY: Association for Computing Machinery. Domingo, D. (2015). Fostering and moderating citizen conversations. In L. Zion \& D. Craig (Eds.), Ethics for digital journalists: Emerging best practices (pp.
164-168). New York, NY: Routledge.

Ellis, J. (2015). What happened after 7 news sites got rid of reader comments. Cambridge, MA: Nieman Journalism Lab.

Freelon, D. (2015). Discourse architecture, ideology, and democratic norms in online political discussion. New Media \& Society, 17(5), 772-791. https://doi.org/ $10.1177 / 1461444813513259$

Freire, F. (2016). Campanhas feministas na Internet: Sobre protagonismo, memes e o poder das redes sociais [Feminist campaigns on the Internet: On leadership, memes and the power of social networks]. Em Debate, 8(5), 26-32.

Gardiner, B., Mansfield, M., Anderson, I., Ulmanu, M., Louter, D., \& Holder, J. (2016, April 12). The dark side of Guardian comments. The Guardian. Retrieved from https://www.theguardian.com/technology/ 2016/apr/12/the-dark-side-of-guardian-comments

Gastil, J., Deess, E. P., \& Weiser, P. J. (2002). Civic awakening in the jury room: A test of the connection between jury deliberation and political participation. Journal of Politics, 64, 585-595.

Gervais, B. T. (2013). Incivility in mass political discourse: The causes and consequences of an uncivil public (Doctoral dissertation).

Gervais, B. T. (2015). Incivility online: Affective and behavioral reactions to uncivil political posts in a webbased experiment. Journal of Information Technology \& Politics, 12(2), 167-185.

Gómez-García, I. (2013). Del meme al imeme, trascendiendo la dimensión lúdica [From meme to imeme, transcending the playful dimension]. Entretextos, 5(15), 1-19.

Goode, L. (2009). Social news, citizen journalism, and democracy. New Media \& Society, 11(8), 1287-1305.

Goodman, E., \& Cherubini, F. (2013). Online comment moderation: Emerging best practices. World Association of News Press. Retrieved from www.wan-ifra.org/reports/2013/10/04/onlinecomment-moderation-emerging-best-practices

Graf, J., Erba, J., \& Harn, R. W. (2017). The role of civility and anonymity on perceptions of online comments. Mass Communication and Society, 20(4), 526-549.

Graham, T., \& Wright, S. (2015). A tale of two stories from "below the line." The International Journal of Press/Politics, 20(3), 317-338. http://www.doi.org/ $10.1177 / 1940161215581926$

Habermas, J. (1984). The theory of communicative action. Boston, MA: Beacon.

Habermas, J. (1992). Moral consciousness and communicative action. Cambridge: Polity Press.

Herbst, T. (2010). Linguistische Aspekte der Synchronisation von Fernsehserien: Phonetik, Textlinguistik, Übersetzungstheorie [Journalistic aspects of the dubbing of television series: Phonetics, text linguistics, translation theory] (Vol. 318). Berlin: Walter de Gruyter.

Hermida, A. (2011). Fluid spaces, fluid journalism. In J. B. Singer, D. Domingo, A. Heinonen, A. Hermida, S. 
Paulussen, T. Quandt, . . . M. Vujnovic (Eds.), Participatory journalism: Guarding open gates at online newspapers (pp. 177-191). Hoboken, NJ: Wiley.

Hille, S., \& Bakker, P. (2014). Engaging the social news user: Comments on news sites and Facebook. Journalism Practice, 8(5), 563-572.

Hwang, H., Kim, Y., \& Kim, Y. (2018). Influence of discussion incivility on deliberation: An examination of the mediating role of moral indignation. Communication Research, 45(2), 213-240.

Jamieson, K. H., Volinsky, A., Weitz, I., \& Kenski, K. (2017). The political uses and abuses of civility and incivility. In K. Kenski \& K. H. Jamieson (Eds.), The Oxford handbook of political communication (pp. 205-217). Oxford: Oxford University Press.

Jensen, E. (2016, August 17). NPR website to get rid of comments. National Public Radio. Retrieved from https://www.npr.org/sections/publiceditor/ 2016/08/17/489516952/npr-website-to-get-ridofcomments

Kies, R. (2010). Promises and limits of web-deliberation. New York, NY: Palgrave Macmillan.

Kothari, C. R. (2004). Research methodology: Methods and techniques. New Delhi: New Age International.

Krippendorff, K. (2018). Content analysis: An introduction to its methodology. Thousand Oaks, CA: Sage.

Ksiazek, T. B., Peer, L., \& Lessard, K. (2016). User engagement with online news: Conceptualizing interactivity and exploring the relationship between online news videos and user comments. New Media \& Society, 18(3), 502-520.

Ksiazek, T. B., Peer, L., \& Zivic, A. (2015). Discussing the news: Civility and hostility in user comments. Digital journalism, 3(6), 850-870.

Lapidot-Lefler, N., \& Barak, A. (2012). Effects of anonymity, invisibility, and lack of eye-contact on toxic online disinhibition. Computers in Human Behavior, 28(2), 434-443.

Larsson, A. O. (2018). Assessing "the regulars" and beyond: A study of comments on Norwegian and Swedish newspaper Facebook pages. Journalism Practice, 12(5), 605-623.

Masip, P. (2011). Comentarios de las noticias: La pesadilla de los cibermedios [News comments: The nightmare of the cybermedia]. Anuario ThinkEPI, 5, 106-111.

Masip, P., Noci, J. D., Domingo, D., Micó, J. L., \& Ruiz, C. (2012). Comments in news, democracy booster or journalistic nightmare: Assessing the quality and dynamics of citizen debates in Catalan online newspapers. International Symposium on Online Journalism, 2(1), 46-64.

McNair, B. (2018). Fake news: Falsehood, fabrication and fantasy in journalism. New York, NY: Routledge.

Meltzer, K. (2015). Journalistic concern about uncivil political talk in digital news media: Responsibility, credibility, and academic influence. The International Journal of Press/Politics, 20(1), 85-107. https://www.doi. org/10.1177/1940161214558748
Meso-Ayerdi, K., Mendiguren-Galdospin, T., \& PérezDasilva, J. (2017). Memes políticos difundidos por usuarios de Twitter: Análisis de la jornada electoral del 26J de 2016 [Political memes spread by Twitter users: Analysis of election day 26J 2016]. El Profesional de la Información, 26(4), 672-683.

Min, S.-J. (2007). Online vs. face-to-face deliberation: Effects on civic engagement. Journal of ComputerMediated Communication, 12, 1369-1387. http:// www.doi.org/10.1111/j.1083-6101.2007.00377.x

Muddiman, A., \& Stroud, N. J. (2017). News values, cognitive biases, and partisan incivility in comment sections. Journal of Communication, 67(4), 586-609.

Mutz, D. C. (2015). In-your-face politics: The consequences of uncivil media. Princeton, NJ: Princeton University Press.

Newman, N., Fletcher, R., Kalogeropoulos, A., \& Nielsen, R. (2019). Digital news report 2019. Oxford: Reuters Institute for the Study of Journalism.

Owens, E. J. (2017). U.S. Patent Application No. 14/939,827. Alexandria, VA: United States Patent and Trademark Office.

Papacharissi, Z. (2004). Democracy online: Civility, politeness, and the democratic potential of online political discussion groups. New Media \& Society, 6(2), 259-283.

Paskin, D. (2010). Say what? An analysis of reader comments in bestselling American newspapers. Journal of International Communication, 16(2), 67-83.

Prochazka, F., Weber, P., \& Schweiger, W. (2018). Effects of civility and reasoning in user comments on perceived journalistic quality. Journalism Studies, 19(1), 62-78.

Robinson, S. (2010). Traditionalists vs. convergers: Textual privilege, boundary work, and the journalistAudience relationship in the commenting policies of online news sites. Convergence, 16(1), 125-143.

Rowe, D. (2014). Following the followers: Sport researchers' labour lost in the twittersphere? Communication \& Sport, 2(2), 117-121.

Rowe, I. (2015). Deliberation 2.0: Comparing the deliberative quality of online news user comments across platforms. Journal of Broadcasting \& Electronic Media, 59(4), 539-555.

Ruiz, C., Domingo, D., Mico, J. L., Díaz-Noci, J., Meso, K., \& Masip, P. (2011). Public sphere 2.0? The democratic qualities of citizen debates in online newspapers. The International Journal of Press/Politics, 16(4), 463-487. http://www.doi.org/10.1177/1940 161211415849

Ruiz, C., Massip, P., Micó-Sanz, J. L., Díaz-Noci, J., \& Domingo, D. (2010). Conversación 2.0. y democracia: Análisis de los comentarios de los lectores en la prensa digital catalana [Conversation 2.0. and democracy: Analysis of reader comments in the Catalan digital press]. Comunicación y Sociedad, 23(2), 7-39.

Salaverría, R. (2019). Digital journalism: 25 years of research. El Profesional de la Información, 28(1), 1-26. 
Santana, A. D. (2014). Virtuous or vitriolic: The effect of anonymity on civility in online newspaper reader comment boards. Journalism Practice, 8(1), 18-33.

Shen, J. (2019, June 14). Making public comments more meaningful. Facebook. Retrieved from https://about.fb.com/news/2019/06/makingpublic-comments-more-meaningful

Sobieraj, S., \& Berry, J. M. (2011). From incivility to outrage: Political discourse in blogs, talk radio, and cable news. Political Communication, 28(1), 19-41.

Springer, N., Engelmann, I., \& Pfaffinger, C. (2015). User comments: Motives and inhibitors to write and read. Information, Communication \& Society, 18(7), 798815. http://www.doi.org/10.1080/1369118X. 2014.997268

Strandberg, K., \& Berg, J. (2013). Online newspapers' readers' comments: Democratic conversation platforms or virtual soapboxes? Comunicação e Sociedade, 23, 132-152.

Stromer-Galley, J., \& Wichowski, A. (2011). Political discussion online. In M. Consalvo \& C. Ess (Eds.), The handbook of internet studies. Oxford: Blackwell.

Stroud, N., Scacco, J. M., \& Curry, A. L. (2014). Interactive features in online news. Austin, TX: Center for Media Engagement.

Stroud, N. J., Scacco, J. M., Muddiman, A., \& Curry, A. L. (2015). Changing deliberative norms on news organizations' Facebook sites. Journal of ComputerMediated Communication, 20(2), 188-203.

Stryker, R., Conway, B. A., \& Danielson, J. T. (2016). What is political incivility? Communication Monographs, 83, 535-556. http://www.doi.org/10.1080/ 03637751.2016 .1201207

Su, L. Y. F., Xenos, M. A., Rose, K. M., Wirz, C., Scheufele, D. A., \& Brossard, D. (2018). Uncivil and personal? Comparing patterns of incivility in comments on the Facebook pages of news outlets. New Media \& Society, 20(10), 3678-3699.

Tenenboim, O., \& Cohen, A. A. (2015). What prompts users to click and comment: A longitudinal study of online news. Journalism, 16(2), 198-217.

Toma, C. L., Hancock, J. T., \& Ellison, N. B. (2008). Separating fact from fiction: An examination of deceptive self-presentation in online dating profiles. Personality and Social Psychology Bulletin, 34(8), 1023-1036.

Vergeer, M. (2018). Incorrect, fake, and false: Journalists' perceived online source credibility and verification behavior. Observatorio Journal, 12(1), 37-52. http:// www.doi.org/10.15847/obsOBS12120181126

Waldron, J. (2012). The harm in hate speech. Cambridge, MA: Harvard University Press.

Weber, P. (2014). Discussions in the comments section: Factors influencing participation and interactivity in online newspapers' reader comments. New Media \& Society, 16(6), 941-957.

Weber, M., Viehmann, C., Ziegele, M., \& Schemer, C. (2020). Online hate does not stay online-How implicit and explicit attitudes mediate the effect of civil negativity and hate in user comments on prosocial behavior. Computers in Human Behavior, 104, 106192.

Wessler, H. (2008). Investigating deliberativeness comparatively. Political Communication, 25(1), 1-22.

Williams, E. P., Russell-Mayhew, S., Nutter, S., Arthur, N., \& Kassan, A. (2018). Weight bias: Twitter as a tool for opening dialogue among broad audiences. Social Networking, 7(3), 111-125.

Ziegele, M. (2016). Nutzerkommentare als Anschlusskommunikation: Theorie und qualitative Analyse des Diskussionswerts von Online-Nachrichten [User comments as media-stimulated interpersonal communication: Theory and qualitative analysis of the discussion value of online news]. Wiesbaden: Springer VS.

Ziegele, M., Breiner, T., \& Quiring, O. (2014). What creates interactivity in online news discussions? An exploratory analysis of discussion factors in user comments on news items. Journal of Communication, 64(6), 1111-1138.

\section{About the Authors}

Orge Castellano Parra is a Journalist and Copywriter and a PhD Candidate and Research Assistant at the University of the Basque Country. His research interests include data journalism, Artificial Intelligence technology, cross-cultural communication, and online discourse.

Koldobika Meso Ayerdi is a Senior Lecturer at the Department of Journalism II of the University of the Basque Country. He has researched online journalism and blogging and organizes the annual International Conference on Online Journalism and Web 2.0 at the University of the Basque Country in Bilbao, Spain.

Simón Peña Fernández is an Associate Lecturer in Journalism in the Department of Journalism II (University of the Basque Country) He holds a degree in Journalism and Audiovisual Communication from the University of Navarra and a PhD in Information Sciences from the University of the Basque Country. 